\title{
Identifikasi Kondisi Hutan Lindung Pulau Sebatik Kabupaten Nunukan Kalimantan Utara
}

\author{
Husmul Beze* \\ Teknologi Rekayasa Perangkat Lunak, Politeknik \\ Pertanian Negeri Samarinda, Samarinda, 75131 \\ husmul@politanisamarinda.ac.id \\ *Corresponding author
}

\author{
Suparjo \\ Teknologi Geomatika, Politeknik Pertanian Negeri \\ Samarinda, Samarinda, 75131 \\ suparjowd@gmail.com
}

\begin{abstract}
In the last ten years the people on Sebatik Island have experienced water shortages. This happened because the forest which is the source of community water dried up. It is estimated that the drying up of these springs is due to changes in the function of forests as water reserves. This change in forest function occurs as a result of the process of clearing forests for plantations or other development activities. This is why it is necessary to analyze the protected forest cover on Sebatik Island. In this study, analysis of forest cover was carried out based on Landsat satellite imagery. To check the correctness of the analysis results on the satellite image, field checks are carried out. Based on the research results, the forest area on Sebatik Island has an area of 2,088.37 ha. The damaged forest is estimated to be 339.97ha, while the protected forest area which is still in good condition has an area of 1,748.40 ha.
\end{abstract}

Kata Kunci- Protected Forest, Sebatik Island, Forest Cover Analysi, Ndvi

\section{PENDAHULUAN}

Pulau Sebatik adalah sebuah pulau di utara Pulau Kalimantan yang langsung berbatasan dengan Negara Malaysia. Sebuah pulau yang berbagi lahan dengan negara tetangga Malaysia ini memiliki peran sangat penting sebagai pintu gerbang Negara Republik Indonesia. Secara administrasi Pulau Sebatik masuk dalam Kabupaten Nunukan. Kabupaten Nunukan kaya akan potensi sumber daya alam yang sebagian diantaranya belum dimanfaatkan secara optimal. Sumber daya alam dan hasil-hasilnya yang merupakan sumber utama penghasilan daerah ini, khususnya dari sektor kehutanan, pertanian, dan pariwisata.

Luas wilayah Kabupaten Nunukan adalah 14.263,68 $\mathrm{Km}^{2}$ terletak pada Provinsi Kalimantan Utara dan wilayah lautan sejauh 4 mil laut dari garis pantai terluar ke arah laut seluas $1.408,758 \mathrm{Km}^{2}$. Secara astronomi terletak pada posisi antara $115^{\circ} 33^{\prime}$ sampai dengan $118^{\circ} 03^{\prime} 00^{\prime}$ Bujur Timur dan 03 $15^{\prime} 00^{\prime}$ ' sampai dengan 04²4'55" Lintang Utara. Wilayah Kabupaten Nunukan di sebelah Utara berbatasan langsung dengan Negara Malaysia Timur (Sabah), sebelah Timur dengan Laut Sulawesi, sebelah Selatan dengan Kabupaten Bulungan dan Kabupaten Malinau, sebelah Barat berbatasan langsung dengan Negara Malaysia Timur yaitu wilayah Serawak (Anonim, 2010).

Rata-rata curah hujan dalam lima tahun (2005-2009) di Kabupaten Nunukan mencapai 212,6 mm per bulan, dengan curah hujan tertinggi $307,1 \mathrm{~mm}$ pada bulan Juli dan terendah 103,8 mm pada bulan Maret (Anonim, 2010). Berdasarkan kondisi hidrologinya, Kabupaten Nunukan dipengaruhi oleh sekitar 10 Aliran Sungai dan 17 pulau, Sungai terpanjang adalah Sungai Sembakung dengan panjang $278 \mathrm{~km}$, sedangkan Sungai Tabut merupakan sungai terpendek dengan panjang $30 \mathrm{~km}$. Sungai ini memiliki Peranan yang cukup penting sebagai sarana Transportasi Air (mobilisasi penduduk, hasil pertanian dan perdagangan) di Kabupaten Nunukan. Selain itu sungai juga merupakan sumber air bagi masyarakat Kabupaten Nunukan, khususnya di Pulau Sebatik.

Tabel 1. Aliran Sungai (DAS) Kabupaten Nunukan

\begin{tabular}{|l|l|l|}
\hline No & \multicolumn{1}{|c|}{ Nama DAS } & Panjang $(\mathrm{km})$ \\
\hline 1 & Sembakung & 278 \\
\hline 2 & Sulunan & 52 \\
\hline 3 & Sepadaan & 32 \\
\hline 4 & Italy & 146 \\
\hline 5 & Sebuku & 115 \\
\hline 6 & Agisan & 62 \\
\hline 7 & Tikung & 50 \\
\hline 8 & Tabut & 30 \\
\hline 9 & Simanggaris & 36 \\
\hline
\end{tabular}

Namun dalam lima tahun terakhir, Pulau Sebatik mengalami kesulitan air luar biasa. Kesulitan air ini semakin menjadi saat musim kemarau tiba. Akibatnya, masyarakat mengandalkan kiriman air dari luar Pulau Kalimantan yang tidak jauh dari Pulau Sebatik. Diperkirakan, kesulitan air ini diakibatkan oleh rusaknya kawasan hutan di pulau ini. Sebagai langkah awal perlu dilakukan penelitian analisa tutupan hutan terhadap Pulau Sebatik. Sebagai identifikasi potensi luasan hutan yang ada di Pulau Sebatik.

\section{METODOLOGI}

A. Waktu dan Tempat Penelitian

Penelitian dilakukan dalam rentang waktu Juni hingga Desember 2014. Proses analisa data dan dokumentasi 
dilaksanakan di Laboratorium SIG dan Indraja Politani Samarinda. Pengecekan lapangan di Pulau Sebatik Kalimantan Utara. lain:

Bahan yang digunakan dalam penelitian ini antara

1) Peta Rencana Tata Ruang Wilayah (RTRW) Provinsi Kalimantan Timur

2) Citra Landsat 8 wilayah Pulau Sebatik

Peralatan yang digunakan dalam penelitian ini adalah sebagai berikut:

1) Komputer atau laptop

2) Global Positioning System (GPS)

3) Kamera

4) Software ER Mapper 7.0

5) Software ArcGis 10

6) Tally Sheet untuk analisa pengambilan contoh vegetasi

7) Tali trafia

8) Alat tulis

B. Prosedur Penelitian

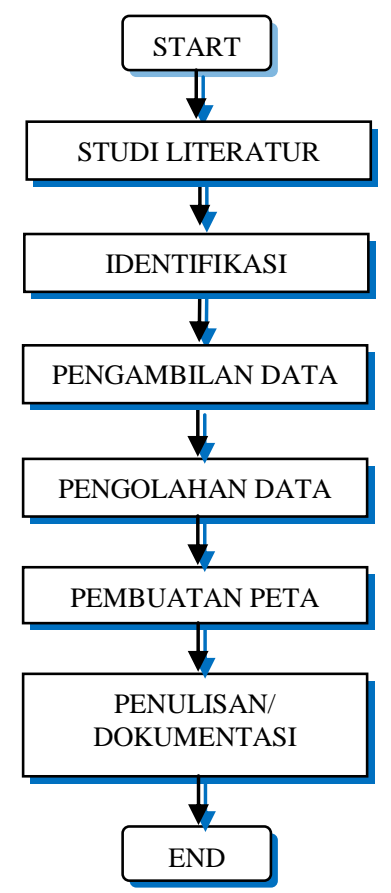

Gambar 1. Diagram Alir Prosedur Penelitian

a. Studi Literatur

Pada tahap ini dilakukan studi literatur tentang kondisi hutan lindung di Pulau Sebatik.

b. Identifikasi Masalah

Pada tahap ini dilakukan proses identifikasi terhadap kondisi tutupan hutan di Pulau Sebatik yaitu menentukan metode klasifikasi tutupan hutan lindungnya.

c. Pengambilan Data

Pada tahap awal penelitian dilakukan analisa citra landsat 8 tahun 2014. Citra landsat 8 diambil dari situs milik NASA Amerika Serikat yaitu di alamat http://www.usgs.gov. Data citra ini digunakan untuk menganalisa kesehatan tutupan vegetasi dengan memanfaatkan komposit band 4, 5 dan 6 .

Untuk memastikan hasil analisa citra maka dilakukan pengecekan lapangan. Pengecekan lapangan dilakukan dengan membuat titik contoh. Metode titik contoh yang digunakan adalah metode "Purposive Sampling". Alasannya agar lokasi contoh mewakili klasifikasi kawasan vegetasi, lokasi contoh berada pada wilayah yang tidak terpotong oleh badan jalan dan/atau sungai dan lokasi contoh mewakili beberapa keadaan kontur wilayah. Untuk memudahkan pengamatan maka dibuat plot contoh dengan berbagai luasan. Hal ini dilakukan untuk memudahkan pengamatan sebaran pohon di titik contoh.

1) Titik contoh ukuran $20 \mathrm{~m} \times 20 \mathrm{~m}$ untuk identifikasi tumbuhan tingkat pohon (diameter $>20 \mathrm{~cm}$ )

2) Titik contoh ukuran $10 \mathrm{~m} \times 10 \mathrm{~m}$ digunakan untuk identifikasi tumbuhan tiang (diameter $10 \mathrm{~cm}$ $<\mathbf{a}<20 \mathrm{~cm})$

3) Titik contoh ukuran $5 \mathrm{~m} \times 5 \mathrm{~m}$ digunakan untuk identifikasi tumbuhan tingkat pancang (tinggi $>1,5 \mathrm{~m}$; diameter $<10 \mathrm{~cm}$ )

4) Titik contoh ukuran $2 \mathrm{~m} \times 2 \mathrm{~m}$ digunakan untuk identifikasi tumbuhan tingkat semai (tinggi $<1,5 \mathrm{~m})$

Data kondisi vegetasi dicatat sesuai dengan tingkatan pertumbuhan (pohon, tiang, pancang, dan semai) menggunakan tally sheet perhitungan vegetasi.

d. Pengolahan Data

Data yang digunakan dalam penelitian ini antara lain :

1) Data primer : data citra landsat 8 dan data kondisi vegetasi hutan mulai dari tingkat pohon, tiang, pancang dan semai. Data kondisi vegetasi yang dimaksud adalah data diamater vegetasi dan spesies vegetasi.

2) Data sekunder : data batas Pulau Sebatik, data jalan, data RTRW Provinsi Kalimantan Timur.

Pada tahap awal penelitian dilakukan analisa kesehatan vegetasi. Metode yang digunakan dalam tahap ini menggunakan metode Normal Difference Vegetation Index (NDVI) dengan rumus :

$$
\frac{\text { Band } 5-\text { Band } 4}{\text { Band } 5+\text { Band } 4}
$$

Hasil analisa NDVI selanjutnya diklasifikasi menggunakan metode ISO unsupervised classification. Klasifikasi ini dilakukan untuk mengidentifikasi kelas kerapatan vegetasi. Dalam penelitian ini tingkat kerapatan vegetasi dibuat dalam 5 kelas. Untuk memastikan hasil analisa klasifikasi dilakukan pengecekan lapangan dengan melakukan pengukuran diameter pohon dan identifikasi jenis vegetasi. 
Tabel 2. Kriteria Awal Tingkat Kerapatan

\begin{tabular}{|c|c|c|}
\hline No. & $\begin{array}{c}\text { Kriteria } \\
\text { Kerapatan } \\
\text { Hutan }\end{array}$ & Parameter \\
\hline 1. & $\begin{array}{l}\text { Sangat } \\
\text { Tinggi }\end{array}$ & $\begin{array}{l}\text { a. Jumlah Pohon> } 175 \\
\text { Pohon } / \mathrm{Ha} \\
\text { b. Tutupan tajuk > } 70 \% \\
\text { c. Indeks Shanon Winner } \\
>3\end{array}$ \\
\hline 2. & Tinggi & $\begin{array}{l}\text { a. Jumlah Pohon 100-175 } \\
\text { pohon/Ha } \\
\text { b. Tutupan tajuk 40-70\% } \\
\text { c. Indeks Shanon Winner } \\
2,51-3\end{array}$ \\
\hline 3. & Sedang & $\begin{array}{l}\text { a. Jumlah Pohon } 61-99 \\
\text { pohon/Ha } \\
\text { b. Tutupan tajuk < } 40 \% \\
\text { c. Indeks Shanon Winner } \\
\text { 2,01-2,5 }\end{array}$ \\
\hline 4. & Jarang & $\begin{array}{l}\text { a. Jumlah Pohon 26-60 } \\
\text { pohon } / \mathrm{Ha} \\
\text { b. Tutupan tajuk =0\% } \\
\text { c. Indeks Shanon Winner } \\
\text { 1-2 }\end{array}$ \\
\hline 5. & $\begin{array}{l}\text { Sangat } \\
\text { Jarang }\end{array}$ & $\begin{array}{l}\text { a. Jumlah Pohon< } 25 \\
\text { pohon/Ha } \\
\text { b. Tutupan tajuk =0\% } \\
\text { c. Indeks Shanon Winner < } \\
1\end{array}$ \\
\hline
\end{tabular}

(1) Uji Ketelitian Hasil Interpretasi Citra

Berdasarkan data vektor vegetasi hasil pengolahan citra Landsat 8 dengan menggunakan metode $N D V I$ dan data sampling vegetasi di lapangan, dilakukan kegiatan uji interpretasi citra dengan rumusan yang kemudian diisi pada Tabel 3.

Tabel 3. Tabel Uji Ketelitian Intepretasi

\begin{tabular}{|c|c|c|c|c|c|c|c|c|}
\hline \multirow[b]{2}{*}{$\begin{array}{c}\text { Uji } \\
\text { Lapang } \\
\text { an }\end{array}$} & \multicolumn{4}{|c|}{ Hasil Intepretasi } & \multirow[b]{2}{*}{$\begin{array}{c}\mathbf{J} \\
\mathrm{ml}\end{array}$} & \multirow[b]{2}{*}{$\begin{array}{c}\mathrm{O} \\
\mathrm{mi} \\
\mathrm{si}\end{array}$} & \multirow{2}{*}{$\begin{array}{c}\mathrm{K} \\
\mathrm{o} \\
\mathrm{mi} \\
\mathrm{si}\end{array}$} & \multirow{2}{*}{$\begin{array}{l}\mathrm{K} \\
\text { et } \\
\text { eli } \\
\text { tia } \\
\mathrm{n}\end{array}$} \\
\hline & A & B & $\mathrm{C}$ & $\begin{array}{c}\text { Lai } \\
n- \\
\text { lain }\end{array}$ & & & & \\
\hline $\begin{array}{c}\text { A } \\
\text { B } \\
\text { C } \\
\text { Lain- } \\
\text { lain } \\
\end{array}$ & & & & & & & & \\
\hline Jumlah & & & & & & & & \\
\hline
\end{tabular}

Keterangan :

$\mathrm{K}=$ Ketelitian hasil interpretasi $(\%)$

$\mathrm{B}=$ Hasil interpretasi yang benar

$\mathrm{S}=$ Jumlah sampel yang diamati

\section{e. Pembuatan Peta}

Pada tahap ini dilakukan proses layout terhadap semua data yang telah diolah pada perangkat lunak
ArcGis. Adapun data-data yang akan dilayout dan dijadikan peta adalah batas administrasi Pulau Sebatik, hasil analisa tutupan lahan Pulau Sebatik, peta hutan lindung Pulau Sebatik dan data atribut.

Langkah berikutnya dari proses pembuatan peta ini adalah mencetak peta dalam ukuran A3 dimana peta sudah dilengkapi dengan kelengkapan peta seperti judul peta, legenda, arah angin, sumber peta, skala, insert dan grid peta.

f.Penulisan / Dokumentasi

Pada tahap ini proses penulisan karya ilmiah yang ditulis dan diterbitkan untuk memaparkan hasil penelitian atau pengkajian yang telah dilakukan.

\section{HASIL DAN PEMBAHASAN}

Berdasarkan hasil analisis citra landsat 8 dengan kombinasi band 564 diperoleh 5 klasifikasi kerapatan vegetasi pada wilayah studi yaitu kerapatan sebagaimana disajikan pada Tabel 3. Untuk klasifikasi rendah dan sangat rendah diintrepetasikan sebagai semak belukar dan tanah terbuka, dimana kawasan tersebut tidak ada tumbuhan berkayu hanya ilalang atau semak belukar.

Tabel 4. Kelas Kerapatan Vegetasi Berdasarkan Analisa NDVI.

\begin{tabular}{|l|lr|l|l|}
\hline No. & Kerapatan & $\begin{array}{l}\text { Ko } \\
\text { de }\end{array}$ & $\begin{array}{l}\text { Indeks } \\
\text { Kerapatan }\end{array}$ \\
\hline 1 & $\begin{array}{l}\text { Kerapatan } \\
\text { sangat tinggi }\end{array}$ & tajuk & V5 & $\begin{array}{l}0,3831873269 \\
\text { s/d } \\
0,5584415584\end{array}$ \\
\hline 2 & $\begin{array}{l}\text { Kerapatan taj.uk } \\
\text { sedang }\end{array}$ & V4 & $\begin{array}{l}0,2078330953 \\
\text { s/d } \\
0,3831873268\end{array}$ \\
\hline 3 & $\begin{array}{l}\text { Kerapatan tajuk } \\
\text { sedang }\end{array}$ & V3 & $\begin{array}{l}0,0326788637 \\
\text { s/d } \\
0,2078330952\end{array}$ \\
\hline 4 & $\begin{array}{l}\text { Kerapatan tajuk } \\
\text { rendah }\end{array}$ & V2 & $\begin{array}{l}-0,1425753681 \\
\text { s/d } \\
\end{array}$ \\
\hline 5 & $\begin{array}{l}\text { Kerapatan tajuk } \\
\text { sangat rendah (terbuka } \\
\text { dan perairan) }\end{array}$ & V1 & $\begin{array}{l}-0,0326788636 \\
\text { s/d } \\
-0,1425753680\end{array}$ \\
\hline
\end{tabular}

Untuk membuktikan hasil analisa terhadap citra maka dilakukan verifikasi lapangan. Kegiatan ini dilakukan pada 2 (enam) lokasi sampel dengan jumlah plot ukur sebanyak 10 plot. Secara rinci lokasi plot-plot contoh tersebut seperti disajikan pada Tabel 5. 
Tabel 5. Penyebaran Lokasi Plot Pengambilan Contoh

\begin{tabular}{|c|c|c|c|}
\hline \multirow{2}{*}{$\begin{array}{c}\text { No. } \\
\text { sample }\end{array}$} & \multicolumn{2}{|c|}{ Koordinat } & \multirow{2}{*}{ Kode } \\
\cline { 2 - 3 } & $\mathrm{X}$ & $\mathrm{Y}$ & \\
\hline 1 & 582007 & 459891 & $\mathrm{~V} 5$ \\
\hline 2 & 581727 & 459619 & $\mathrm{~V} 4$ \\
\hline 3 & 581703 & 459530 & $\mathrm{~V} 3$ \\
\hline 4 & 581621 & 459566 & $\mathrm{~V} 2$ \\
\hline 5 & 581516 & 459474 & $\mathrm{~V} 1$ \\
\hline 6 & 583978 & 459145 & $\mathrm{~V} 5$ \\
\hline 7 & 583896 & 459224 & $\mathrm{~V} 4$ \\
\hline 8 & 583970 & 459221 & $\mathrm{~V} 3$ \\
\hline 9 & 584071 & 459215 & $\mathrm{~V} 2$ \\
\hline 10 & 583228 & 459402 & $\mathrm{~V} 1$ \\
\hline
\end{tabular}

Pada lokasi contoh dibuat 5 plot ukur vegetasi sesuai dengan masing-masing kelas kerapatan yaitu kelas tingkat pohon (diameter $>20 \mathrm{~cm}$ ) menggunakan plot ukur vegetasi dengan ukuran 20 meter x 20 meter, tingkat tiang $(10 \mathrm{~cm}<\varnothing<20 \mathrm{~cm})$ menggunakan plot ukur dengan ukuran 10 meter x 10 meter, sedangkan untuk tingkat pancang (tinggi $>1,5 \mathrm{~m}$; diameter $<10 \mathrm{~cm}$ ) menggunakan plot ukur dengan ukuran

5 meter x 5 meter, dan untuk tingkat semai (tinggi $<1,5 \mathrm{~m}$ ) menggunakan plot ukur dengan ukuran 2 meter x 2 meter.

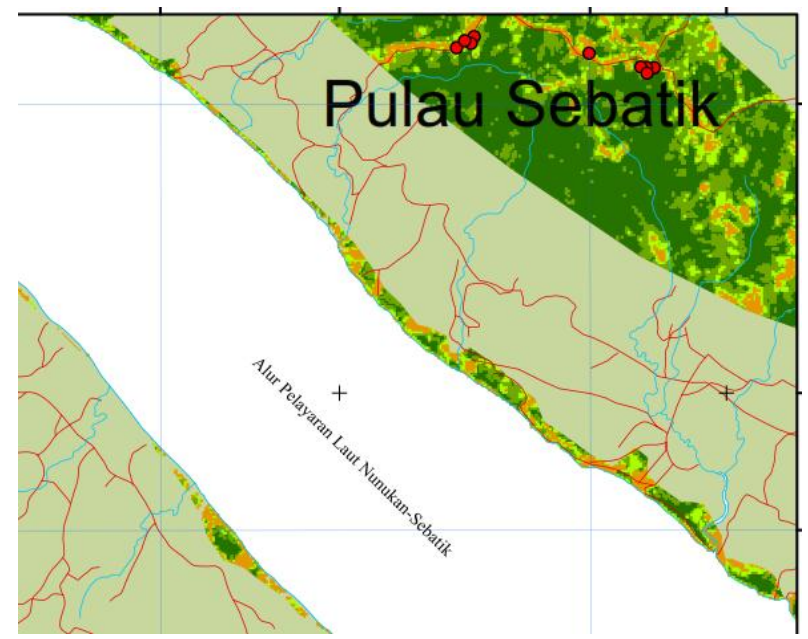

Gambar 2. Gambar Peta Sebaran Titik Contoh Penelitian

Hasil verifikasi lapangan terhadap jumlah pohon memberikan gambaran bahwa ada tiga kelas kerapatan tutupan hutan di Hutan Lindung Pulau Sebatik

Tabel 6. Jumlah Rata-Rata Pohon pada Setiap Kelas Kerapatan

\begin{tabular}{|c|c|c|c|}
\hline No & $\begin{array}{c}\text { Kelas } \\
\text { Kerapatan }\end{array}$ & N/ha & Persen tutupan (\%) \\
\hline 1 & V5 & 142.9 & 100 \\
\hline 2 & V4 & 50 & 35 \\
\hline 3 & V3 & 12.5 & 8,75 \\
\hline
\end{tabular}

Keterangan $\mathrm{N}=$ Jumlah pohon per hektar.
Pada plot dengan kondisi kerapatan tinggi hasil pengecekan lapangan menunjukan bahwa di lokasi tersebut terdapat jumlah pohon rata-rata 142,9 pohon per hektar. Berdasarkan kriteria kerapatan pohon maka kelompok ini termasuk memiliki kerapatan tinggi. Pada plot kerapatan sedang terdapat jumlah pohon rata-rata 50 pohon per hektar atau termasuk kerapatan jarang. Plot dengan kerapatan rendah terdapat jumlah pohon rata-rata 12,5 pohon per hektar atau termasuk kerapatan sangat jarang.

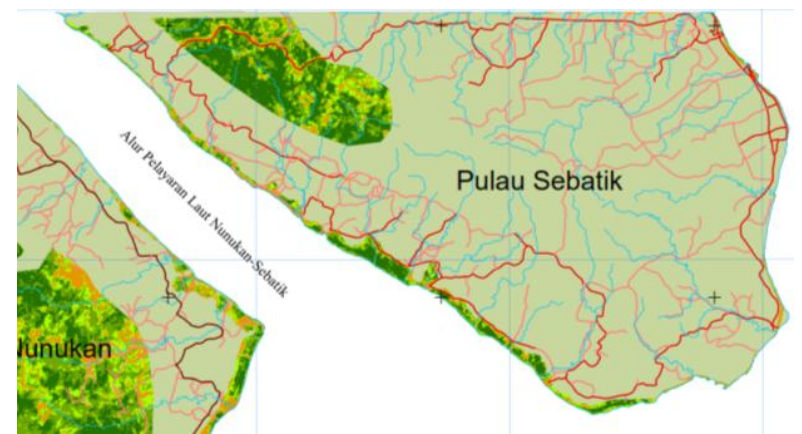

Gambar 3. Gambar Hasil Klasifikasi NDVI pada Hutan Lindung Pulau Sebatik

Jika dilihat dari tutupan lahannya maka hasil pengelompokan tutupan lahan di Pulau Sebatik menggunakan Citra Landsat 8 menunjukan bahwa plot kelompok kerapatan tinggi adalah hutan memiliki tingkat tutupan vegetasi $100 \%$, plot kelompok kerapatan sedang memiliki tutupan vegetasi $35 \%$ dan plot dengan kerapatan rendah memiliki tutupan vegetasi $8,75 \%$. Asumsi tersebut didasarkan bahwa pada citra Landsat tutupan lahan stratum paling atas yaitu tingkat pertumbuhan pohon, sedangkan stratum bawah hingga ke lantai hutan tidak terdeteksi.

Berdasarkan perhitungan luas bidang dasar setinggi dada tingkat pohon dan tingkat tiang diketahui bahwa rata-rata luas bidang dasar per hektar pada setiap kelas kerapatan vegetasi seperti disajikan pada Tabel 7.

Tabel 7. Luas Bidang Dasar Per Hektar Kelas Kerapatan.

\begin{tabular}{|c|c|c|}
\hline No & Kelas Kerapatan & LBD (m2/ha) \\
\hline 1 & Tinggi (V5) & 24,117 \\
\hline 2 & Sedang (V4) & 5,434 \\
\hline 3 & Rendah (V3) & 0,662 \\
\hline
\end{tabular}

Tabel 7 memperlihatkan bahwa kelas kerapatan tinggi di lapangan memiliki luas bidang dasar $24,117 \mathrm{~m}^{2} /$ ha, kelas kerapatan sedang $5,434 \mathrm{~m}^{2} /$ ha dan kelas kerapatan rendah $0,662 \mathrm{~m}^{2} / \mathrm{ha}$. Kondisi tegakan pada setiap fase pertumbuhan tegakan dapat digambarkan melalui analisis vegetasi. Secara umum rata-rata jumlah pohon berdasarkan fase pertumbuhan dapat dilihat pada Tabel 8 . 
Tabel 8. Rata-rata Jumlah Individu Pohon Pada Setiap Fase Pertumbuhan.

\begin{tabular}{|c|c|r|}
\hline No & Tingkat Pertumbuhan & \multicolumn{1}{|c|}{ N/ha } \\
\hline 1 & Pohon & 98,3 \\
\hline 2 & Tiang & 345,5 \\
\hline 3 & Pancang & $1.150,0$ \\
\hline 4 & Semai & $18.333,3$ \\
\hline
\end{tabular}

Secara deskriptif dapat dijelaskan bahwa kondisi tegakan di hutan Pulau Pulau Sebatik memiliki distribusi seperti pada umumnya hutan alam lainnya. Uji interpretasi dilakukan untuk mengetahui tingkat ketelitian pemetaan kelas kerapatan vegetasi pada wilayah studi . Uji ini dilakukan pada data yang diperoleh dari citra Landsat 8 dengan menggunakan algoritma NDVI dengan perbandingan jumlah sampel yang diambil adalah 2 titik plot ukur yang mewakili semua jenis kelas kerapatan. Hasilnya memperlihatkan bahwa intepretasi citra sama dengan kondisi lapangan.

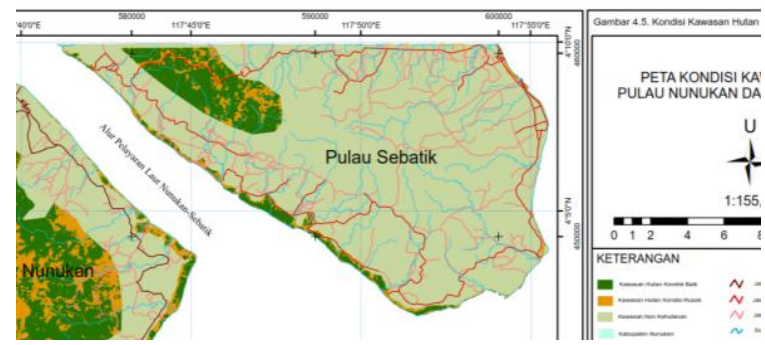

Gambar 4. Gambar Peta Kondisi Hutan Lindung Pulau Sebatik, Kabupaten Nunukan, Kalimantan Utara

Kawasan hutan lindung pada Pulau Sebatik memiliki luas 2.088,37 ha. Menurut hasil analisa, hutan lindung di Pulau Sebatik masuk dalam klasifikasi hutan yang rusak dengan luas sebesar 339,97 Ha, sedangkan untuk wilayah hutan lindung yang masih dalam kondisi baik seluas $1.748,40 \mathrm{Ha}$. Kondisi kawasan hutan lindung tersebut dapat dilihat pada Tabel 8.

Tabel 9. Kondisi Kawasan Hutan pada Pulau Sebatik

\begin{tabular}{|c|c|c|c|}
\hline \multicolumn{2}{|c|}{ Kriteria } & Kelas & $\begin{array}{c}\text { Kawasan } \\
\text { Hutan Lindung }\end{array}$ \\
\hline Kerapatan & $\begin{array}{l}\text { Kondisi } \\
\text { Hutan }\end{array}$ & & \\
\hline $\begin{array}{l}\text { Sangat } \\
\text { Tinggi }\end{array}$ & \multirow{2}{*}{ Baik } & 5 & $1.131,49$ \\
\hline Tinggi & & 4 & 616,91 \\
\hline \multicolumn{3}{|c|}{ Sub Total } & $1.748,40$ \\
\hline Sedang & \multirow{3}{*}{ Rusak } & 3 & 235,00 \\
\hline Rendah & & 2 & 102,36 \\
\hline $\begin{array}{l}\text { Sangat } \\
\text { rendah }\end{array}$ & & 1 & 2,61 \\
\hline \multicolumn{3}{|c|}{ Sub Total } & 339,97 \\
\hline & & Total & $2.088,37$ \\
\hline
\end{tabular}

Kerusakan hutan lindung sebagian besar berada pada wilayah sekitar hutan lindung yang memiliki akses jalan. Kerusakan tersebut dilakukan oleh masyarakat sekitar dengan membuka wilayah hutan lindung untuk rumah, kebun pisang, kebun kakao dan perkebunan sawit.

\section{KESIMPULAN}

Berdasarkan hasil kajian di lapangan, tutupan hutan di Pulau Sebatik banyak mengalami kerusakan. Penyebab kerusakan hutan diakibatkan oleh beberapa faktor diantaranya pendukung antara lain keberadaan prasarana jalan yang membelah kawasan hutan lindung, kondisi topografi ringan yang memudahkan aktivitas masyarakat, adanya fasilitas umum di kawasan hutan lindung seperti adanya layanan listrik dari PLN dan Pola pengelolaan kawasan hutan yang belum sesuai tata ruang.

\section{DAFTAR PUSTAKA}

Anonim. 2014. Kaltim Dalam Angka 2014. Samarinda BPS Kaltim.

Derita Djuman dan Suharyono, 2007. Perubahan Penutupan Lahan Hutan Lindung Bontang Berdasarkan Intepretasi Citra Landsat. Samarinda. Rimba Kalimantan.

Molidena Elis dan As-syakur Abd Rahman. 2012. Karakteristik Pola Spektral Vegetasi Hutan dan Tanaman Industri Berdasarkan Data Penginderaan Jauh. Makassar. Prosiding Pertemuan Ilmiah MAPIN XIX.

Purwanto Anang Dwi dkk. 2014. Analisis Sebaran dan Kerapatan Mangrove Menggunakan Citra Landsat 8 di Segara Anakan Cilacap. Bogor. Prosiding Seminar Nasional Penginderaan Jauh Lapan. 